\title{
TREATMENT OF TOBACCO DEPENDENCE, A CRITICAL GAP IN CZECH CLINICAL PRACTICE GUIDELINES
}

\author{
Kamila Zvolská ${ }^{1}$, Keely Fraser ${ }^{1,2}$, Miroslav Zvolský, Eva Králíková1,2 \\ ${ }^{1}$ Centre for Tobacco-Dependent of the 3rd Medical Department, Department of Endocrinology and Metabolism, First Faculty of Medicine, \\ Charles University and General University Hospital in Prague, Prague, Czech Republic \\ 2Institute of Hygiene and Epidemiology, First Faculty of Medicine, Charles University and General University Hospital in Prague, Prague, Czech \\ Republic \\ ${ }^{3}$ Institute of Health Information and Statistics, Prague, Czech Republic
}

\begin{abstract}
SUMMARY
Objective: Tobacco related comorbidities and treatment of dependence are relevant to clinicians of all disciplines. Clinicians should provide a brief intervention about tobacco use with smokers at each clinical contact (success rate of 5-10 \%). Intensive treatment (success rate > 30\%) should be available to those who need it. Brief intervention is not yet standard clinical practice. Our aim was to assess clinical practice guidelines (CPG) of selected medical professional societies to determine whether or not tobacco dependence treatment recommendations were included.

Methods: Between October and December 2013, we conducted a keyword search of CPG for 20 medical professional societies in the Czech Republic. We searched for the keywords "smoking", "tobacco" and "nicotine addiction" in 91 CPG documents, which were freely available on the websites of selected professional societies. We focused specifically on CPG relating to cardiovascular and respiratory diseases as well as cancer. We excluded any CPG focused on acute conditions, diagnostics only, laboratory methods, or administration.

Results: There was no mention of smoking in 27.7\% (26/94) of CPG documents. Only 16\% (15/94) of CPG documents listed smoking as a risk factor. 42.5\% (40/94) mentioned smoking related phrases (e.g. "smoking ban"). Only 13.8\% (13/94) of CPG included a section on tobacco dependence, referenced tobacco dependence treatment guidelines or mentioned specialized treatment centres where smokers can be referred.

Conclusion: Nearly one third of CPG related to cardiovascular and respiratory diseases as well as cancer made no mention of smoking. Despite the clinical significance of smoking, the majority of CPG did not adequately address tobacco dependence and its treatment.
\end{abstract}

Key words: tobacco dependence, brief intervention, treatment, clinical practice guidelines, Czech Republic

Address for correspondence: K. Zvolská, Centre for Tobacco-Dependent of the 3rd Medical Department, Department of Endocrinology and Metabolism, First Faculty of Medicine, Charles University and General University Hospital in Prague, Karlovo náměsti 32, 12800 Prague 2, Czech Republic. E-mail: kamila.zvolska@vfn.cz

https://doi.org/10.21101/cejph.a4720

\section{INTRODUCTION}

Smoking is the leading cause of preventable death globally (1). Cardiovascular diseases (CVD) are the most common cause of death among smokers. In the Czech Republic (CR), about 2,000 more people die annually due to CVD than to lung cancer, the most common form of cancer caused by smoking (2). Overall mortality in the CR due to smoking is about 14,000 people a year (2). Compared to developed Western countries of the EU, the prevalence of smoking in the CR is high - $29 \%$ (33\% men, $24 \%$ women) $(3,4)$. The prevalence of smoking in the CR undoubtedly contributes to the country's high cardiovascular mortality rate, which is almost two times greater than that of other European countries (15 European Union member states before 2004) (5).

Tobacco dependence is a chronic disease characterized by relapse and remission, which can be reported according to the International Classification of Diseases 10 (ICD-10) code F17
$(6,7)$. The quit rate among smokers who stop without help or using methods with placebo effect is about $2-5 \%$ after one year $(6,8)$. According to the WHO, all physicians should provide a brief intervention for tobacco use to a patient at each clinical contact. The success rate of brief intervention is 5-10\% (9). A brief intervention consists of 5 points known as the " 5 A's". The intervention involves asking the patient about tobacco use, advising the patient to quit, assessing readiness to quit, assisting the patient in quitting, and arranging for follow up (9). People unable to quit should be recommended to receive intensive specialized treatment. The success rate with intensive treatment (psychobehavioural therapy and pharmacotherapy) provided by specialized Centres for Tobacco-Dependent (CTD) in the CR is over $30 \%$ after one year $(10,11)$.

Brief intervention with patients who smoke is still not standard clinical practice in the CR. Eighty percent of Czech physicians ask about tobacco use and advise patients to quit. Beyond this, subsequent parts of the brief intervention are delivered to smokers 
i.e. assessing readiness to quit, assisting the patient to quit, and arranging for follow up (12).

According to the National Institute of Health, clinical practice guidelines (CPG) are systematically developed statements to assist practitioners and patients in making appropriate decisions about health care for specific clinical circumstances (13). CPG help support the transfer of research knowledge into clinical practice. Tobacco related comorbidities and treatment of tobacco dependence are relevant to clinicians of all disciplines. According to the WHO there should be a systematic approach for incorporating brief tobacco interventions into primary health care services (11).

Our aim was to determine whether or not tobacco dependence treatment recommendations were included in selected CPG documents for cardiovascular and respiratory diseases, cancer and related comorbidities from various medical disciplines.

\section{MATERIALS AND METHODS}

In the Czech Republic, there are approximately 120 medical professional societies. Most of these societies are part of the
Czech Medical Association of Jan Evangelista Purkyně (CzMA) (14). We selected 20 societies (Table 1) in the fields of internal and general medicine or oncology that had published CPG on their websites. These documents were freely accessible online as of December 2, 2013. We then selected current CPG from each society that addressed education, treatment or prevention of diseases related to smoking as a risk factor. We excluded CPG that addressed acute conditions, diagnostics only, laboratory methods, or administration.

We searched for keywords "smoking", "tobacco" and "nicotine addiction" in the full text of 94 selected CPG documents. Documents were reviewed to determine if smoking was mentioned as a risk factor (RF) or if they included any recommendations relating to intervention or treatment.

According to the results of the keyword search, we classified the CPG documents into four groups: CPG with no mention of smoking; CPG that reported smoking as a RF; CPG that included two word recommendation to stop or minimize smoking; CPG with a comprehensive approach that included recommendation to use a brief intervention, a link to the Centres for tobacco-dependent, or guidelines for tobacco dependence treatment $(15,16)$.

Table 1. Tobacco dependence treatment recommendations in selected Clinical Practice Guidelines (CPG) of medical professional societies in the Czech Republic

\begin{tabular}{|c|c|c|c|c|c|}
\hline \multirow[b]{2}{*}{ Medical professional society $(n=20)$} & \multicolumn{5}{|c|}{ Number of selected CPG } \\
\hline & $\begin{array}{l}\text { No mention } \\
\text { of smoking }\end{array}$ & $\begin{array}{l}\text { Smoking as } \\
\text { a risk factor }\end{array}$ & $\begin{array}{l}\text { Recommenda- } \\
\text { tion to stop } \\
\text { smoking }\end{array}$ & $\begin{array}{l}\text { Comprehensive } \\
\text { approach }\end{array}$ & Total \\
\hline $\begin{array}{l}\text { Cerebrovascular Section of the Czech Neurological } \\
\text { Society }\end{array}$ & 0 & 0 & 6 & 1 & 7 \\
\hline Czech Society of Angiology & 1 & 0 & 1 & 0 & 2 \\
\hline Czech Diabetes Society & 2 & 3 & 4 & 1 & 10 \\
\hline Czech Society of Internal Medicine CzMA & 0 & 0 & 2 & 2 & 4 \\
\hline Czech Society of Cardiology & 2 & 3 & 4 & 2 & 11 \\
\hline Czech Society of Nephrology & 0 & 0 & 1 & 0 & 1 \\
\hline Czech Society for the Study of Obesity & 1 & 0 & 1 & 0 & 2 \\
\hline Czech Society for Oncology & 0 & 0 & 0 & 1 & 1 \\
\hline Czech Paediatric Society & 1 & 0 & 0 & 0 & 1 \\
\hline $\begin{array}{l}\text { Czech Pneumological and } \\
\text { Phthiseological Society }\end{array}$ & 3 & 4 & 11 & 0 & 18 \\
\hline Czech Society for Atherosclerosis & 0 & 0 & 1 & 1 & 2 \\
\hline Czech Society for Hypertension & 0 & 0 & 1 & 0 & 1 \\
\hline Czech Society for Thrombosis and Haemostasis & 6 & 0 & 0 & 0 & 6 \\
\hline Society of Occupational Medicine & 1 & 0 & 0 & 0 & 1 \\
\hline Czech Society for Metabolic Bone Diseases & 0 & 1 & 0 & 0 & 1 \\
\hline Czech Society of Gastroenterology & 2 & 0 & 1 & 0 & 3 \\
\hline Czech Society of Haematology & 3 & 0 & 0 & 0 & 3 \\
\hline Czech Society of Hepatology & 1 & 0 & 0 & 0 & 1 \\
\hline Czech Menopause and Andropause Society & 0 & 0 & 1 & 0 & 1 \\
\hline Czech Society of General Practice & 3 & 4 & 6 & 5 & 18 \\
\hline
\end{tabular}




\section{RESULTS}

Among all CPG documents related to cardiovascular and respiratory diseases as well as cancer, $27.7 \%$ (26/94) did not mention smoking. 16\% (15/94) of documents listed smoking among risk factors. $42.5 \%$ (40/94) of CPG included some recommendation to stop or minimize smoking (e.g. "smoking ban"). 13.8\% (13/94) of CPG recommended a comprehensive approach to treatment or prevention of tobacco use.

CPG documents which included no mention of smoking in the diagnosis and treatment included venous thromboembolism, diabetic retinopathy, atrial fibrillation, chronic pulmonary hypertension, obesity, cystic fibrosis, interstitial lung disease, tuberculosis, malignant pleural mesothelioma, chronic pancreatitis, colorectal cancer, malignant lymphoma, hepatocellular cancer, and dyslipidemia.

Many CPG documents mentioned smoking only as a RF in the introduction, and rarely mentioned tobacco use in terms of primary and secondary prevention.

Smoking related recommendations were often included in the non-pharmacological treatment section of CPG. The most frequently mentioned smoking related recommendations, in descending order, included; smoking ban, cessation, abstinence, elimination, and quit smoking/stop smoking. The terms smoking minimization, avoiding smoking, warning against smoking, smoking omission, give-up smoking, and restriction on smoking were each mentioned only once in the 94 CPG documents we reviewed.

Only two professional societies had a link to the Guidelines for Tobacco Dependence Treatment on their website (Czech Society of Cardiology and Czech Society for Oncology).

The Prevention of Cardiovascular Diseases in Adults - Joint Guidelines of Czech Professional Societies (2005) is the only CPG document that fully addressed tobacco dependence treatment (17).

\section{DISCUSSION}

Despite the clinical significance of smoking, few medical professional societies in the Czech Republic adequately addressed tobacco dependence and treatment in their CPG documents. One quarter of the selected CPG documents did not include any mention of smoking. Only $16 \%$ of CPG named smoking as a risk factor for cardiovascular and respiratory diseases, cancer, and related comorbidities.

Forty two percent of CPG documents contained a recommendation to quit smoking, most often using the phrase "smoking ban". Some documents used terms such as "minimize" or "restrict smoking". It would be appropriate to replace these terms with a clear recommendation for patients to stop smoking. This means zero exposure to tobacco smoke, including secondhand smoke. The ultimate goal for patients is smoking cessation, not reduction because there is no safe level of tobacco exposure (18). If we recommend that tobacco-dependent patients reduce the number of cigarettes without medication, the patient smokes the reduced number of cigarettes more intensively. This is known as compensatory smoking as it allows the patient to obtain the required dose of nicotine with fewer cigarettes and reduces withdrawal symptoms $(19,20)$.
The majority ( $80 \%$ ) of smokers are physically addicted to nicotine and cannot stop smoking without help $(21,22)$. It is therefore important to proactively offer smokers treatment and information on where they can seek help, when they are ready to quit.

In this study, we focused on CPG because they are a key component of evidence-based medicine (23). CPG from the Czech Society of Cardiology state that "no drug can reduce cardiovascular mortality, by $25-50 \%$, as effectively as smoking cessation" (24). Only $14 \%$ of the selected CPG documents included the points of a brief intervention, a more detailed section on tobacco dependence treatment or a link to the Guidelines for Tobacco Dependence Treatment. CPG from the UK's National Institute for Health and Care Excellence (NICE) may be a good example of how tobacco treatment guidelines can be incorporated into the Czech CPG. The NICE guidelines state that one of the points of care for the patient with a concrete diagnosis of nicotine dependence is to offer advice to quit smoking, and provides links to the guidelines for brief interventions and Smoking Cessation Services in the UK (25-27).

Limitations of this study may include the parameters of CPG documents selected, the changing number of medical professional societies, the availability of CPG freely online, as well as the number of CPG documents published by each society. We chose only CPG documents related to clinical practice of cardiovascular and respiratory diseases, and cancer. However, all physicians should intervene with smokers regardless of their area of specialization. A brief intervention for tobacco dependence is simple, quick (3-5 minutes), and effective (9). It would be well justified to recommend that a brief intervention should be conducted with all smokers. Tobacco dependence treatment guidelines should be included in all CPG, including those that were not included in this survey.

The presence of a short description of the brief intervention or reference to the Guidelines for tobacco dependence treatment in CPG documents may help remind physicians of the importance of routinely providing a brief intervention to patients who smoke. More recent research has shown a shorter form of the 5 A's model to be effective for busier clinics or providers. The Mayo Clinic, Rochester, MN, USA uses the 2 A's (Ask, Advice) and R (Refer) to the Nicotine Dependence Centre (28-30). The treatment in specialized Centres for Tobacco-Dependent (CTD) (31) in the Czech Republic is carried out according to current evidence based guidelines $(9,15)$.

Since 2013, the Czech Society for Tobacco Dependence Treatment has begun to advocate that professional societies include more detailed information on tobacco dependence treatment in forthcoming updates of any CPG documents.

\section{CONCLUSION}

CPG documents from selected medical professional societies in the Czech Republic did not adequately address the importance of smoking cessation. Smoking cessation should not be viewed as a mere lifestyle change, but rather imperative to good health and a necessary part of treatment for many diseases. CPG are an important source of evidence based information for clinicians. CPG should provide up to date information on tobacco dependence, treatment and highlight the importance of using brief intervention with patients who smoke at each clinical contact. 


\section{Conflict of Interests}

KZ, MZ a EK are members of the Czech Medical Association of Jan Evangelista Purkyně. There are no other conflicts of interests.

\section{Funding}

The study was financed by the Internal Grant Agency of the Ministry of Health of the Czech Republic (IGA MZ) grant number NT12170-5 and Charles University Research Development Schemes (PROGRES 025/LF1).

\section{REFERENCES}

1. World Health Organization. Fresh and alive. WHO Report on the global tobacco epidemic, 2008: The MPOWER Package [Internet]. Geneva: WHO; 2008 [cited 2014 Nov 10]. Available from: http://www.who.int/ tobacco/mpower/mpower report full 2008.pdf.

2. Peto R, Lopez AD, Boreham J, Thun M. Mortality from smoking in developed countries 1950-2000. 2nd ed. [Internet]. Geneva: International Union Against Cancer; 2006 [cited 2014 Nov 10]. Available from: http:// www.deathsfromsmoking.net/download\%20files/Original\%20research/ Mortality $\% 20$ from $\% 20$ smoking\%20in $\% 20$ developed $\% 20$ countries $\% 20$ 1950-2000\%20(2nd\%20ed.).pdf.

3. Cifkova R. Epidemiology of cardiovascular diseases. Postgrad Med 2006;8 Suppl Prev Kardiol:6-12. (In Czech.)

4. Sovinová H, Sadílek P, Csémy L. Development of smoking prevalence in the adult population of the Czech Republic 1997 - 2011 [Internet]. Praha: SZÚ; 2012 [cited 2014 Nov 10]. Available from: http://www.szu. cz/uploads/documents/czzp/zavislosti/koureni/zprava-kuractvi-2011.pdf.

5. Molarius A, Parsons RW, Dobson AJ, Evans A, Fortmann SP, Jamrozik $\mathrm{K}$, et al.; WHO MONICA Project. Trends in cigarette smoking in 36 populations from the early 1980 s to the mid-1990s: findings from the WHO MONICA Project. Am J Public Health. 2001 Feb;91(2):206-12.

6. Hughes JR, Keely J, Naud S. Shape of the relapse curve and long-term abstinence among untreated smokers. Addiction. 2004 Jan;99(1):29-38.

7. International Classification of Diseases and Related Health Problems, 10th revision, second updated edition [Internet]. WHO; Institute of Health Information and Statistics of the Czech Republic; 2011 [cited 2014 Nov 10]. Available from: http://www.uzis.cz/cz/mkn/index.html.

8. Nicotine addiction in Britain: a report of the Tobacco Advisory Group of the Royal College of Physicians. London: Royal College of Physicians of London; 2000.

9. Fiore MC, Jaén CR, Baker TB; United states public Health Service. Treating tobacco use and dependence: 2008 update. Clinical Practice Guideline. Rockville, MD: U.S. Department of Health and Human Services, Public Health Service; 2008.

10. Kralikova E, Kmetova A, Stepankova L, Zvolska K, Davis R, West R. Fifty-two-week continuous abstinence rates of smokers being treated with varenicline versus nicotine replacement therapy. Addiction. 2013 Aug;108(8):1497-502.

11. World Health Organization. Tobacco Free Initiative (TFI). Health system and professionals [Internet]. Geneva: WHO [cited 2014 Nov 10]. Available from: http://www.who.int/tobacco/control/health professionals/en/ index3.html.

12. Kralikova E, Kmetova A, Stepankova L, Zvolska K, Felbrova V, Kulovana $\mathrm{S}$, et al. Treatment of tobacco dependence in the Czech Republic. In: XIIIth Annual Meeting of the SRNT-Europe: abstract book; 2011 Sep 8-11; Antalya, Turkey. p. 175

13. Field MJ, Lohr KN. Guidelines for clinical practice: from development to use [Internet]. Washington: Committee on Clinical Practice Guidelines, Division of Health Care Services; 1992 [cited 2014 Nov 10]. Available from: http://www.nap.edu/openbook.php?isbn=0309045894.

14. Czech Medical Association of Jan Evangelista Purkyně. Medical societies and syndicates/CMA JEP [Internet]. Prague: CMA JEP [cited 2014 Nov 10]. Available from: http://www.cls.cz/spolecnosti-cls-jep. (In Czech.)
15. Králíková E, Češka R, Pánková A, Štěpánková L, Zvolská K, Felbrová V, Kulovaná S, Zvolský M. Tobacco dependence treatment guidelines. Vnitr Lek. 2015 May;61(5 Suppl 1):1S4-1S15. (In Czech.)

16. Society for Tobacco Dependence Treatment. Centres for tobacco addicts [Internet]. Prague: Society for Tobacco Dependence Treatment [cited 2014 Nov 10]. Available from: http://www.slzt.cz/centra-lecby. (In Czech.)

17. Cífková R, Býma S, Češka R, Horký K, Karen I, Kunešová M, et al. Joint guidelines of Czech Professional Societies: the prevention of cardiovascular diseases in adults. Klin Biochem Metab. 2005;13/34(4):212-24. (In Czech.)

18. U.S. Department of Health and Human Services. The health consequences of smoking - 50 years of progress: a report of the surgeon general [Internet]. Atlanta: U.S. Department of Health and Human Services; 2014 [cited 2014 Nov 10]. Available from: http://www.surgeongeneral.gov/ library/reports/50-years-of-progress/full-report.pdf.

19. Shahab, L. Smoking reduction [Internet]. National Centre for Smoking Cessation and Training (NCSCT); 2012 [cited 2014 Nov 10]. Available from: http://www.ncsct.co.uk/usr/pub/Briefing\%202.pdf.

20. Tobacco: harm-reduction approaches to smoking. NICE public health guidance 45 [Internet]. Manchester: NICE; 2013 [cited 2014 Nov 10]. Available from: http://www.ncsct.co.uk/usr/pub/NICE Harm reduction. pdf.

21. Balfour DJ, Wright AE, Benwell ME, Birrell CE. The putative role of extra-synaptic mesolimbic dopamine in the neurobiology of nicotine dependence. Behav Brain Res. 2000 Aug;113(1-2):73-83.

22. Stead LF, Bergson G, Lancaster T. Physician advice for smoking cessation. Cochrane Database Syst Rev. 2008 Apr 16;(2):CD000165. doi: 10.1002/14651858.CD000165.pub3.

23. Brownson RC, Baker EA, Leet TL, Gillespie KN, True WR. Evidencebased public health. Second edition [Internet]. Oxford University Press; 2011 [cited 2014 Nov 10]. Available from: http://file.zums.ac.ir/ ebook/473-Evidence-Based\%20Public\%20Health,\%202nd\%20EditionRoss\%20C.\%20Brownson,\%20Elizabeth\%20A.\%20Baker-0195397894Oxf.pdf.

24. Widimský P, Janoušek S, Vojáček J. Guidelines for diagnosis and treatment of acute myocardial infarction [Internet]. Czech Society of Cardiology; 2002 [cited 2014 Nov 10]. Available from: http://www. kardiochirurgie.cz/dokumenty/cks1.pdf. (In Czech.)

25. National Institute for Health and Care Excellence. Type 2 diabetes: the management of type 2 diabetes. NICE clinical guideline 87 [Internet]. NICE; May 2009 [updated 2014 Dec; cited 2014 Dec 12]. Available from: https://www.nice.org.uk/guidance/CG87.

26. National Institute for Health and Care Excellence. Smoking: brief interventions and referrals. Public health guidaline PH1 [Internet]. NICE; Mar 2006 [cited 2014 Nov 10]. Available from: http://www.nice.org.uk/ guidance/PH1.

27. National Institute for Health and Care Excellence. Stop smoking services. Public health guidaline PH10 [Internet]. NICE; Feb 2008 [updated 2013 Nov; cited 2014 Nov 10]. Available from: http://www.nice.org.uk/guidance/ph10.

28. Hurt RD, Ebbert JO, Hays JT, McFadden DD. Treating tobacco dependence in a medical setting. CA Cancer J Clin. 2009 Sep-Oct;59(5):314-26.

29. Schroeder SA. What to do with a patient who smokes. JAMA. 2005 Jul 27;294(4):482-7.

30. Campbell E, Walsh RA, Sanson-Fisher R, Burrows S, Stojanovski E. A group randomised trial of two methods for disseminating a smoking cessation programme to public antenatal clinics: effects on patient outcomes. Tob Control. [Internet]. Apr 2006 [cited 2014 Nov 10];15(2):97-102. Available from: http://www.ncbi.nlm.nih.gov/pmc/articles/PMC2563553.

31. Society for Tobacco Dependence Treatment [Internet]. Society for Tobacco Dependence Treatment [cited 2014 Nov 10]. Available from: http:// www.slzt.cz. (In Czech.) 